\title{
Antioxidant and Anti-inflammatory Effects of Alpha- Lipoic Acid in Collagen II-induced Arthritis in Rats
}

\author{
Mona F. El-Karn \\ Department of Medical Physiology, Faculty of Medicine, Assiut University
}

\begin{abstract}
Background: Rheumatoid arthritis (RA) is a progressive, chronic inflammatory disease with uncertain pathogenesis. It is characterized by polyarthritis and high concentrations of pro-inflammatory cytokines. There is a growing body of evidence indicates that free radicals play an important role in the pathophysiology of the chronic inflammatory state associated with rheumatoid arthritis. Alpha-lipoic acid $(\alpha-L A)$ is a naturally occurring dithiol compound which is known to elicit a unique set of biochemical activities with potential potent biological antioxidant effect. Also, it may play a role in modulation of various inflammatory signaling pathways. Objective: The purpose of this study was to assess the efficacy of alpha-lipoic acid ( $\alpha$ $L A)$, to attenuate the development of rheumatoid arthritis in rat model of collageninduced arthritis. Also, the study discussed the possible mechanisms by which $\alpha-L A$ can alleviate the severity of rheumatoid arthritis. Methods: The study was carried on 30 of female rats divided into 3 groups: control group (group I), Collagen II-induced arthritis group (group II) and CII + alpha lipoic acid treated group (group III). Rheumatoid arthritis was induced in rats of group II by immunization

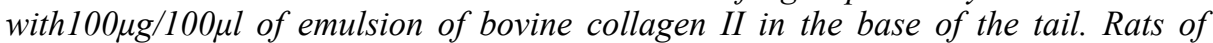
group III were injected by CII, and received $\alpha-L A$ daily $(100 \mathrm{mg} / \mathrm{kg} /$ day/ intraperitonially) for 42 day. Clinical evaluation of arthritis and follow up of body weight was done in all groups throughout the experiment to assess the development and severity of arthritis. Biochemical analysis of blood samples of all groups has been done to evaluate some markers of oxidative stress and inflammation markers. So, plasma levels of lipid peroxides (LPO), nitric oxide (NO) and superoxide dismutase (SOD) were measured for the evaluation of oxidative stress. Also, plasma levels of prostaglandin E2 (PGE2), C-reactive protein (CRP) and tumor necrosis factor- $\alpha \quad(T N F-\alpha)$ ) were measured for evaluation of inflammation. Results: By end of the study, injection of rats of group II with collagen II induced arthritic manifestations in all rats of this group with gradually progressive decrease of mean body weight continued till end of the experiment. Treatment of rats of group III with $\alpha-L A$ led to improvement of most of the clinical arthritic parameters with significant attenuation in body weight loss in this group as compared to rats of group II. There is a significant increase in plasma level of oxidative stress markers in all rats of group II as indicated by increased serum level of lipid peroxides (LPO) and nitric oxide (NO), with a significant reduction in plasma level of superoxide dismutase (SOD) when compared with levels of control group. Also, the study revealed a significant increase in plasma level of inflammatory markers e.g., prostaglandin and C-reactive protein (PGE2 and CRP) as well as increase in plasma level of the pro-inflammatory cytokine; TNF- $\alpha$ in CIA rats (group II). Administration of $\alpha-L A$ to rats of group III
\end{abstract}


induced significant reduction of plasma level of LPO and NO with significant increase in plasma level of SOD as compared with group II. Additionally, there is a significant reduction in plasma levels of the measured inflammatory markers $\left(\left(P G E_{2}\right.\right.$, $C R P$ and TNF- $\alpha$ ) in rats of group III as compared with group II. Conclusion: It could be concluded that $\alpha$-LA has a role to prevent oxidative stress and to support antioxidant system against oxidative damage in collagen-induced arthritis model rats. Also, amelioration of joint damage in CIA rats by $\alpha-L A$ was associated with inhibition of inflammatory process as indicated by lowering plasma level of TNF- $\alpha$, prostaglandin and C-reactive protein. Results of the present study indicate that $\alpha-L A$ may be a new adjunctive therapy for rheumatoid arthritis as it has a potent antioxidant as well as anti-inflammatory effect. Collectively, these findings may encourage further exploration of the usefulness of lipoic acid in arthritis.

\section{INTRODUCTION}

Rheumatoid arthritis (RA) is a chronic, progressive erosive inflammatory disease of the synovium whose pathogenesis is uncertain. Genetic and environmental factors play a role in the pathogenesis ${ }^{(1)}$. The prevalence of RA is about $1 \%$ of the population of the world. Females have a higher incidence (3:1) than males ${ }^{(2)}$. Rheumatoid arthritis is a lifelong disease, although patients can go into remission. Disease progression ultimately leads to disability, and in its most severe forms, RA is associated with increased mortality ${ }^{(3)}$. The disease is characterized by synovitis with infiltration of synovial tissue with inflammatory cells which produce various inflammatory cytokines and growth factors, are intimately involved in a variety of symptoms of $\mathrm{RA}^{(4,5)}$. These cytokines, notably tumor necrosis factor-alpha $(\mathrm{TNF}-\alpha)^{(6)}$ and interleukin-6 (IL-6) ${ }^{(7)}$, may promote the development of osteoclasts ${ }^{(8)}$, which increases bone erosion and systemic bone loss ${ }^{(9)}$.

It has already been demonstrated that reactive oxygen species (ROS) are increasingly produced by inflammatory cells in response to stimulation by pro-inflammatory cytokines such as TNF- $\alpha$, IL-1 and IL6. These ROS act as a messenger of the intracellular signaling pathway (nuclear factor-kappa B-“NF-kB"), suggesting that ROS in turn activate inflammatory cells that have a part in the progression of inflammation ${ }^{(\mathbf{1 0}, 11)}$. Generation of hydroxyl radical in RA patients seems able to modify the structure of human $\mathrm{IgG}$, thereby increasing the production of rheumatoid factors, the biologic hallmark of the disease ${ }^{(12)}$. ROS are highly reactive chemical species, which are formed during normal aerobic metabolism in cells and after the activation of phagocytes during infection or inflammation ${ }^{(13)}$. Cells are normally protected from ROS-induced damage by a variety of endogenous scavenging proteins, enzymes and chemical compounds that constitute the endogenous antioxidant systems $^{(14)}$. It has been reported that ROS destroy antioxidant systems (in fact antioxidant systems are impaired in RA) and that RA patients are thus exposed to oxidant stress and lipid peroxidation because of the reduced antioxidant defence system ${ }^{(15)}$. 
Recent studies indicated that reactive oxygen species (ROS) play an important role in the development of RA, in that in these patients the antioxidant system is impaired and peroxidation reactions are accelerated $^{(1)}$. Epidemiological studies have shown that RA occurs in previously healthy subjects who have low levels of circulating antioxidants, implying a pathogenic role of increased oxidative stress in the development of RA. Targeting of ROS could have a therapeutic value in arthritis as a strategy to reduce the development of inflammation. Many therapeutic trials have assessed the clinical value of antioxidants administration in RA in an effort to restore a normal pool of ROS scavengers ${ }^{(16,17)}$.

Alpha lipoic acid (also known as thioctic acid), has a high reactivity with oxygen free radicals and potential activity as a strong free radical scavenger. Alpha lipoic acid $(\alpha-L A)$ has generated considerable clinical interest as a potent scavenger of reactive oxygen species as it quenches singlet oxygen, hydroxyl radical and hypochlorus $\operatorname{acid}^{(18)}$. Alpha lipoic acid is considered as a unique metabolic antioxidant as this small molecule is soluble in both water and fat. This is significant because water soluble antioxidant nutrients (vitamin $\mathrm{C}$ for example) are found within the cell and fat soluble antioxidants (vitamin $\mathrm{E}$ for example) are found on the cell membrane. Because Alpha lipoic acid ( $\alpha$-LA) works both inside the cell and at the membrane level, it can give a dual protection $^{(\mathbf{1 9})}$.
Lipoic acid contains two thiol groups, which may be oxidized or reduced; both forms of lipoic acid are antioxidants $^{(20)}$. Most antioxidant substances can be oxidized and reduced and usually can only act as antioxidants when they are in their reduced form. Alpha lipoic acid is unique in that both its oxidized and reduced forms possess antioxidant properties. Alpha lipoic acid is able to inhibit free radical reactions from such diverse sources as those generated from the body's own metabolism or from various environmental sources ${ }^{(21)}$.

Alpha lipoic acid is a naturally occurring compound that is synthesized in small amounts by plants and animals; including humans ${ }^{(22,23)}$. In humans, $\alpha$-LA is synthesized in liver and other tissues and is also obtained from both animal and plant sources in the diet. It is readily absorbed from the diet. $\alpha$-LA is found in animal tissues with extensive metabolic activity such as heart, liver, and kidney. The plant sources of $\alpha$-LA, listed from highest to lowest, are spinach, broccoli, tomatoes, peas, brussel sprouts, and rice bran ${ }^{(20)}$.

Immunization of rats with collagen II (CII) leads to development of arthritis "the collagen-induced arthritis model for RA"(24). Rat type II collagen (CII)-induced arthritis (CIA) is commonly used as an animal model of RA because it includes some of the clinical and pathological features similar to those of human RA. It is usually used to investigate mechanisms relevant to RA as well as new antiarthritic treatments ${ }^{(25)}$. 
Aim of the work:

The purpose of the present study was to assess effect of alpha-lipoic acid $(\alpha$-LA $)$ to attenuate the development of rheumatoid arthritis in rat model of collagen II-induced arthritis (CIA). Clinical and biochemical assessment of many arthritic parameters have been studied in this work to evaluate the potentially protective effect of $\alpha$-LA administration in CIA rats.

\section{MATERIALS \& METHODS}

\section{Animals:}

Thirty healthy female albino rats, their body weight ranged 150-170 g were included in the present study. All animals were conditioned at room temperature and natural photoperiod for 1 week before the start of the experiment. A commercial balanced diet and tap water were provided. The duration of experiment was 42 days.

Animals grouping:

Rats were randomly divided into 3 groups (10 rats each) as the following:

1- Control group: group I

2- Collagen II-induced arthritis (CIA) group (group II): injected with bovine collagen II as described by Terato et al., ${ }^{(26)}$.

3- CII + alpha lipoic acid ( $\alpha$-LA ) treated group (CIA+ $\alpha$-LA group): group III. Rats of group III were injected by CII, and received $\alpha$-LA daily in a dose of $100 \mathrm{mg} / \mathrm{kg} / \mathrm{day} /$ intraperitoneally as mentioned by Lee et al., ${ }^{(1)}$, from the beginning of CII injection for 42 days. $\alpha$-LA was purchased from Sigma Chemical (St. Louis, MO, USA).
Methods:

I- Induction of Collagen II-induced arthritis (CIA): CIA was induced as previously described by Terato et al., ${ }^{\text {(26) }}$. Briefly, collagen type II (CII) was dissolved in $0.01 \mathrm{~N}$ acetic acid and emulsified in an equal volume of complete Freund's adjuvant (CFA) containing $\quad 1 \mathrm{mg} / \mathrm{ml}$ heat-killed Mycobacterium tuberculosis (SigmaAldrich). Rheumatoid arthritis was induced by the initial immunization with $100 \mu \mathrm{g} / 100 \mu \mathrm{l}$ emulsion by an intradermal injection in the base of the tail. Twenty one days later after the initial immunization, rats received a booster intradermal injection of bovine $\mathrm{CII}$.

-Animals of different groups were sacrificed under light anesthesia at the end of the experiment. Blood samples from all groups were collected from the orbital vein in heparinized tubes and were centrifuged at $5000 \mathrm{rpm}$ for $10 \mathrm{~min}$ for plasma separation. Plasma samples were divided into aliquots and kept at $-40{ }^{\circ} \mathrm{C}$ until biochemical analysis.

II- Clinical evaluation of arthritis:

All rats of group II and group III were inspected every third day after CII injection to assess the development and severity of arthritis. Each paw of all rats was inspected for signs of inflammation as swelling, erythema or both. Also, signs of arthritis in the joints (namely, wrist, knee and ankle joints) as swelling, tenderness and movement limitation had been assessed.

III- Follow up of body weight:

Changes in body weight were monitored with electronic scale for rats of all groups. Body weight for every rat in each group was evaluated 
5 times: at the first day of the experiment (day 0), 2 weeks after induction of arthritis (day 15), just before injection of the booster dose (day 21), one week after booster dose (day 28) and finally at the end of the experiment (day 42).

\section{IV-Biochemical analysis}

In this study, measurement of markers of oxidative stress and inflammation has been done. So, the study measured the following parameters:

1. Plasma levels of lipid peroxides (LPO) were measured according to the method described by Thayer et al., (27).

2. Plasma level of nitric oxide (NO) was determined by the method of Van Bezooijen et al., ${ }^{(28)}$.

3. Plasma level of superoxide dismutase (SOD) was determined according to the method of Misra and Fridovich $^{(29)}$.

4. Plasma level of prostaglandin $\mathbf{E}_{2}$ (PGE $_{2}$ ) was determined by an ELISA kit for quantitative determination of prostaglandin E2, Cat. No. 900-001, manufactured by Assay Designs Inc. Correlate EIA. Ann Arbor, Michigan USA. The measurement was performed according to the method described by the manufacture.

5. Plasma level of C-reactive protein (CRP) was determined by an ELISA kit for quantitative determination of C-reactive protein. The kit was manufactured by Helica Biosystem, Inc. The measurement was performed according to the method included with the kits.
6. Plasma level of tumor necrosis factor- $\alpha \quad$ (TNF- $\alpha$ ) was determined by an ELISA commercial kit "Rat TNF- $\alpha$ ", it was obtained from KOMA Biotech Product Description, Catalog No: K0921181. The measurement was performed according to the method included with the kits.

Statistical analysis:

All values were expressed as the mean \pm standard error $(\mathrm{M} \pm \mathrm{SE})$. The statistical significance between two groups was analyzed by student t-test. $\mathrm{P}$ value $<0.05$ was considered to represent a significant difference. Spearman's correlation test was also used to study correlation between groups with a range from -1 to 1 .

\section{RESULTS}

I- Clinical assessment of collagen IIinduced arthritis (CIA) and role of o-LA:

- Rats of group II (CIA group): By the end of the study, it was observed that arthritis had been successfully created in all rats of group II. Signs of arthritis were varied from mild swelling and/or redness of the paw or one digit till severe arthritis affecting most of the joints, led to limitation of all movement of the rat. The initial signs of arthritis in most animals of group II were evident at day 13, all animals gave signs of arthritis at day 18; they were maintained arthritic until the end of the experiment. The first manifestation of the disease was mild swelling and/or redness of the paw, followed by erythema and swelling of one or 
more joints, followed by involvement of most of the joints. The course of the disease was progressive. Four days after injection of the booster dose, the intensity of arthritis increased markedly in all rats of group II, nearly, all rats can not move from severity of the pain and the swelling of the joints.

- Rats of group III (CII+ $\alpha$-LA): Rats of group III showed marked attenuation in the incidence of development of arthritis (less than half of the rats). Also, severity of induced arthritis is much less than those in rats of group II. Animals showed only mild swelling and erythema affecting only one or two joints. No increase in the intensity of arthritis after injection of the booster dose. No restriction in the movement observed in rats of this group. The course of arthritis is regressive with marked clinical improvements of all rats of group III when compared with group II. At the end of the study, most rats showed normal clinical picture as those of control group.

\section{II- Follow up of body weight:}

In the first 2 weeks, the normal gain in body weight was comparable in all groups, and no significant differences were seen between them. Rats of control group (group I) showed gradual, progressive weight gain through out whole duration of the experiment. By end of the study, control rats gained more than $25 \%$ of their original weight at the beginning of the study. Rats of Group II (CIA group) began to show less weight gain than the control rats after 2 weeks. By the day 21, a significant decrease in body weight $(\mathrm{p}<0.01)$ was observed in CIA rats compared with the control rats. After that, the mean body weight of CIA group showed progressive gradual decrease continued till end of the experiment (day 42). The highest body weight loss was significant at 4 and 6 weeks in the CIA group, in comparison with the control group $(\mathrm{p}<0.001)$.

Daily injection of rats of group III with $\boldsymbol{\alpha}$-LA $100 \mathrm{mg} / \mathrm{kg} / \mathrm{day}$ significantly attenuated the loss in body weight in this group relative to weights of rats of group II. Rats of group III exhibited slightly significant loss of normal weight gain at the onset of arthritis (day 21) as compared to control group $(\mathrm{p}<0.05)$, but slowly regained weight during the following days. At the end of the study, group III showed non significant difference in their body weight $(\mathrm{p}>0.05)$ in comparison to control group. (Table 1).

III- Effect of $\alpha$-LA on plasma levels of lipid peroxides, nitric oxide and superoxide dismutase in CIA rats:

Table (2) showed that plasma levels of oxidative stress markers (lipid peroxides and nitric oxide) were highly significantly increased $(\mathrm{p}<0.001)$ in CIA group (group II) as compared to the control group (group I). Additionally, plasma level of antioxidant enzyme, superoxide dismutase (SOD) was significantly decreased $(p<0.001)$ in CIA rats as compared with those of control rats.

6 weeks injection of $\alpha$-LA to animals of group III caused a significant reduction in levels of lipid peroxides $(p<0.001)$ and nitric oxide $(p<0.01)$ when compared by group II. Also, plasma level of SOD showed 
highly significant increase $(\mathrm{p}<0.001)$ in rats of group III as compared to those of group II.

Comparing mean values of oxidative indices parameters of group III with those of the control values, LPO and S.O.D showed non significant difference $(p>0.05)$, but NO level still showing significant increase $(\mathrm{p}<0.5)$ as compared to control values (Table 2).

IV- Effect of $\alpha$-LA on plasma levels of inflammatory and proinflammatory mediators in CIA rats:

Animals of group II (CIA) showed very highly significant increase in inflammatory markers, prostaglandin and C-reactive protein (PGE2 and CRP) 6 weeks after initial immunization with $\mathrm{CII}$ as compared with group I $(p<0.001$ for each). Animals of group III (CII $+\alpha$-LA treated group) showed highly significant reduction in inflammatory markers as compared with group II $(\mathrm{p}<.001$ for each) (Table 4).

Plasma level of TNF- $\alpha$ was found to be significantly higher $(p<0.001)$ in group II than group I. Animals of group III (CII $+\alpha$-LA treated group) showed significant reduction in TNF$\alpha$ as compared with group II $(\mathrm{p}<.001)$.

Comparing levels of PGE2, CRP and TNF- $\alpha$ of group III with those of control one showed non significant $(p>0.5)$ change for CRP and TNF- $\alpha$, but PGE2 still showed significant $(\mathrm{p}<0.5)$ increase (Table 3).

V- Correlation between plasma level of TNF- $\alpha$ and changes in body weight in CIA group (group II):

Decrease body weight of group II rats showed very highly significant $(\mathrm{P}<0.001)$ positive correlation with the increase in plasma level of TNF- $\alpha$ of the same group, indicating the possible role of this pro-inflammatory cytokine in decreasing body weight after induction of arthritis (Table 4).

Table (1): Changes in body weight (in gram) in all rat groups over different time intervals through the 42 day of the study

\begin{tabular}{|l|l|l|l|}
\hline Bays & $\begin{array}{l}\text { Group I } \\
\text { n-10 }\end{array}$ & $\begin{array}{l}\text { Group II } \\
\text { n- } 10\end{array}$ & $\begin{array}{l}\text { Group III } \\
\text { n- } 10\end{array}$ \\
\hline $\begin{array}{l}\text { 0 day } \\
\text { P value }\end{array}$ & $159.67 \pm 0.13$ & $\begin{array}{l}162.72 \pm 0.12 \\
\text { ns }\end{array}$ & $\begin{array}{l}157.53 \pm 0.16 \\
\text { Ns }\end{array}$ \\
\hline $\begin{array}{l}\text { 15 day } \\
\text { P value }\end{array}$ & $173.33 \pm 0.14$ & $\begin{array}{l}171.03 \pm 0.08 \\
\text { ns }\end{array}$ & $\begin{array}{l}170.59 \pm 0.05 \\
\text { Ns }\end{array}$ \\
\hline $\begin{array}{l}\text { 21 day } \\
\text { P value }\end{array}$ & $183.49 \pm 0.15$ & $\begin{array}{l}161.18 \pm 0.04 \\
* *\end{array}$ & $\begin{array}{l}171.62 \pm 0.05 \\
*\end{array}$ \\
\hline $\begin{array}{l}\text { 28 day } \\
\text { P value }\end{array}$ & $191.68 \pm 0.10$ & $\begin{array}{l}149.68 \pm 0.05 \\
* * *\end{array}$ & $\begin{array}{l}179.28 \pm 0.04 \\
*\end{array}$ \\
\hline $\begin{array}{l}\text { 42 day } \\
\text { P value }\end{array}$ & $204.76 \pm 0.14$ & $\begin{array}{l}131.21 \pm 0.04 \\
* * *\end{array}$ & $\begin{array}{l}197.16 \pm 0.05 \\
\text { Ns }\end{array}$ \\
\hline
\end{tabular}

Values are mean $\pm \boldsymbol{S E}$.

$\mathbf{N}=$ number of rats / group.

$\boldsymbol{P}$ value of all groups was versus control group. B.W: body weight in grams.

O day: First day, just before starting injection. Group I: control group

Group (II): CIA treated

ns: non significant $(p>0.05)$.

Group (III): $C I A+\alpha-L A$ treatment group

$(*)$ : significant at 0.05 .

(**): Highly significant at 0.01 .

(***): Very highly-significant at 0.001 
Table (2): Effect of $\alpha$-LA on plasma levels of lipid peroxides, nitric oxide and superoxide dismutase in CIA rats

\begin{tabular}{|c|c|c|c|c|}
\hline Groups & n & $\begin{array}{l}\text { LPO } \\
(\mu \mathrm{mol} / \mathrm{L})\end{array}$ & NO $(\mu \mathrm{mol} / \mathrm{L})$ & $\begin{array}{l}\text { S.O.D } \\
\text { (U/L.) }\end{array}$ \\
\hline Group I & 10 & $4.83 \pm 0.231$ & $6.64 \pm 0.167$ & $4.90 \pm 0.437$ \\
\hline $\begin{array}{l}\text { Group II } \\
\text { P1 } \\
\text { P2 }\end{array}$ & 10 & $\begin{array}{l}17.61 \pm 0.876 \\
* * * \\
* * *\end{array}$ & $\begin{array}{l}12.32 \pm 0.35 \\
* * * \\
* *\end{array}$ & $\begin{array}{l}0.98 \pm 0.863 \\
* * * \\
* * *\end{array}$ \\
\hline $\begin{array}{l}\text { Group III } \\
\text { P3 }\end{array}$ & 10 & $\begin{array}{l}6.02 \pm 0.088 \\
\text { ns }\end{array}$ & $\begin{array}{l}9.08 \pm 0.187 \\
*\end{array}$ & $\begin{array}{l}3.97 \pm 0.326 \\
\text { Ns }\end{array}$ \\
\hline
\end{tabular}

Values are Mean \pm SE (Standard error)

LPO: lipid peroxides

S.O.D: superoxide dismutase

Group (II): CIA treated group

number of rats/group.

NO: nitric oxide

Group (I): control group

P1: significant as compared group II to group I by T-test

P2: significant as compared group III to group II by T-test.

P3: significant as compared group III to group I by T-test.

ns: non significant $(p>0.05)$.

(*): significant at 0.05 .

(**): Highly significant at 0.01 .

(***): Very highly-significant at 0.001

Table (3): Effects of $\alpha$-LA on plasma level of inflammatory mediators in CIA rats

\begin{tabular}{|l|l|l|l|l|}
\hline Groups & $\mathbf{n}$ & $\begin{array}{l}\text { PGE }_{\mathbf{2}} \\
\mathbf{p g} / \mathbf{m L}\end{array}$ & $\begin{array}{l}\text { CRP } \\
\mathbf{n g} / \mathbf{m l}\end{array}$ & $\begin{array}{l}\text { TNF-a } \\
(\mathbf{p g} / \mathbf{m l})\end{array}$ \\
\hline Group I & 10 & $116.8 \pm 4.6$ & $350.6 \pm 28.9$ & $10.89 \pm 3.83$ \\
\hline Group II & 10 & $672.3 \pm 25.7$ & $787.5 \pm 29.8$ & $26.63 \pm 3.56$ \\
P1 & & $* * *$ & $* * *$ \\
P2 & & $* * *$ & $* * *$ & $* * *$ \\
\hline Group III & 10 & $\begin{array}{l}180.8 \pm 20.6 \\
\text { P3 }\end{array}$ & $\begin{array}{l}401 . \pm 23.4 \\
\text { ns }\end{array}$ & $\begin{array}{l}13.31 \pm 1.56 \\
\text { Ns }\end{array}$ \\
\hline
\end{tabular}

Values are Mean \pm SE (Standard error)

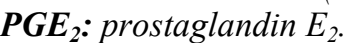

$\boldsymbol{n}=$ number of rats/group.

TNF- $\alpha$ : tumor necrotic factor- $\alpha$

Group (II): CIA treated group

CRP: $C$-reactive protein.

Group (I): control group

P1: significant as compared group II to group I by T-test

P2: significant as compared group III to group II by T-test.

P3: significant as compared group III to group I by T-test.

ns: non significant $(p>0.05)$.
$(* * *)$ : Very highly significant at 0.001 .

(*): significant at 0.05 . 
Table (4): Correlation between plasma level of TNF- $\alpha$ \& body weight in CIA rats

\begin{tabular}{|l|l|l|}
\hline \multirow{2}{*}{ Variable } & TNF- $\boldsymbol{\alpha}$ & $\mathbf{P}$ \\
\cline { 2 - 3 } & $\mathbf{r}$ & $* * *$ \\
\hline Body weight & 0.973 & \\
\hline
\end{tabular}

(***): Very highly-significant (by Spearman correlation test).

TNF- $\alpha$ : tumor necrotic factor- $\alpha$

\section{DISCUSSION}

Rheumatoid arthritis (RA) is a chronic inflammatory disease characterized by synovitis involving synovial hyperplasia with neoangiogenesis and infiltration of lymphocytes and macrophages into the synovial tissue ${ }^{(30)}$. Although laboratory testing and imaging studies can help confirm the diagnosis and track disease progress, rheumatoid arthritis primarily is a clinical diagnosis and no single laboratory test is diagnostic ${ }^{(31)}$. Rat type II collagen (CII)-induced arthritis (CIA) is commonly used as an animal model of RA. In particular, the CIA model has been widely used for the pharmacologic evaluation of antirheumatic drugs ${ }^{(32)}$.

Although the etiology of RA remains undefined, a large body of data suggests that ROS are very likely to play a major role in the pathogenesis of this disease ${ }^{(33)}$. There are many studies which have reported the important participation of ROS in RA pathophysiology. It has been shown that the effects of free radicals can be removed by the administration of antioxidant agents ${ }^{(34)}$.

The present study was performed to evaluate the potential antioxidant effect of $\alpha$-LA on some of the clinical and biochemical parameters in CIA model of RA. Intraperitoneal injection of rats of group II with collagen type II (CII) resulted in development of arthritis in all rats. Signs of arthritis varied from mild swelling and/or redness of the paw or one digit till severe arthritis affecting most of the joints, led to limitation of all movements of the rat. Treatments to rats of group III with $\alpha$-LA led to improvement in most of the clinical arthritic parameters. There was marked attenuation in severity and incidence of development of arthritis in $\alpha$-LA treated rats compared to non treated CIA rats. The course of arthritis is regressive with marked clinical improvements of all rats of group III when compared with group II. These findings were in agreement with those of other investigators $^{(35,36,37,38)}$. Treatment with $\alpha$-LA resulted in a great reduction in tissue swelling and osteophyte formation in the model of chronic arthritis as well as edema formation in the model of acute arthritis ${ }^{(39)}$.

Follow up of body weight of rats of group II (CIA group) showed progressive gradual decrease of mean body weight continued till end of the experiment. Daily treatment of rats of group III with $\alpha$-LA significantly attenuated loss in body weight in this group relative to weights of rats of group II. This was in accordance with the finding of Kuwamoto et al., $2007,{ }^{(40)}$ who reported that the mean 
body weight decreased gradually in CIA rats. Also, in 2008, Martin et al. ${ }^{(41)}$ recorded that CII-induced arthritis is a model of rheumatoid arthritis that induces cachexia. Arthritis decreases food intake both due to marked restriction of movement of the animal due to severe pain and joint swelling as well as due to anorexia associated with chronic inflammatory condition. They suggested that in chronic arthritis, decrease adipose tissue weight is secondary to a reduced adipose lipogenesis, and this effect is not mainly due to the decrease in food intake. However, the mechanism by which arthritis reduces fat stores is not well known. In 2006, Granado et al. ${ }^{(42)}$ reported that fat mass loss in rheumatoid arthritis can be secondary to an increase in lipolysis and/or a decrease in lipogenesis. Another study reported that induced arthritis decreased body weight due to enhanced protein breakdown as well as decreased food intake ${ }^{(43)}$. Data indicate that arthritis-induced decrease in body weight is not only due to a decrease in food intake, but also related to metabolic alterations that result in a dramatic decrease of adiposity. In 2007, Lacasa et al., ${ }^{(44)}$ postulated that prolonged elevation of cytokines in adipose tissue due to inflammatory reactions and decrease food intake can be the main causes of body weight reduction in chronic arthritis. Among these proinflammatory cytokines, TNF- $\alpha$ has been reported to decrease lipogenesis.

The present study showed that intraperitoneal injection of rats of group II with collagen type II (CII) resulted in a significant increase in plasma level of oxidative stress markers as indicated by increased serum level of lipid peroxides (LPO) and nitric oxide (NO) as well as a significant reduction in plasma level of the antioxidant enzyme; superoxide dismutase (SOD) in all animals of that group as compared to levels of control group. These findings were consistent with the findings of other investigators who recorded an increase in plasma level of oxidative stress markers as well as a reduction in plasma level of many of antioxidants in case of rheumatoid arthritis $^{(45,46,47,48)}$. In 2007, Tastekin et al. ${ }^{(49)}$ recorded that lipid peroxidation is thought to be one of the important determinants of joint damage during RA course. Increased plasma levels of lipid peroxides and nitric oxide may be attributed to oxidative stress induced by CII injection. In case of CIA, free radicals have been increased in joint cavity first, and then start its effects on the vessel wall with a consequent origination of edema. The occurrence and progression of this structural damage in RA has been reported to be due to superoxide and hydrogen peroxide radicals ${ }^{(50)}$.

Sources of ROS in inflamed joints are numerous. Osteoclasts ${ }^{(51)}$, chondrocytes $^{(52)}$ synovial cells, neutrophils/macrophages ${ }^{(53)}$ and fragmented particles of degraded extracellular matrix (which activate synovial cells and neutrophils to release ROS) are excellent sources of $\mathrm{O}_{2}$. Role of ROS and, in particular, of superoxide in the degradation of cartilage and bone is not surprising. Cartilage is sensitive to degradation by superoxide and superoxide dismutase (SOD) strongly inhibits this 
degradation $^{(\mathbf{5 4})}$. Furthermore, ROS degrade synovial fluids and depolymerize hyaluronic acid, which leads to a loss of viscosity in the joint, and induction of bone resorption ${ }^{(55)}$.

Cells are normally protected from ROS-induced damage by a variety of endogenous scavenging proteins, enzymes and chemical compounds that constitute the endogenous antioxidant systems ${ }^{(\mathbf{5 6})}$. It has been reported that ROS destroy antioxidant systems and that RA patients are thus exposed to oxidant stress and lipid peroxidation because of the reduced antioxidant defence system ${ }^{(\mathbf{5 7})}$.

In 2005, Cuzzocrea et al. ${ }^{(58)}$ reviewed that as there is a growing body of evidence indicates that ROS perpetuates the chronic inflammatory state associated with RA, thus, it follows that one approach to treating $\mathrm{RA}$ is to remove these reactive oxygen species (ROS). So, a number of antioxidants have been tested in CIA model in the attempt to limit the oxidative damage. Alpha lipoic acid has generated considerable clinical interest as a potent natural antioxidant agent ${ }^{(\mathbf{5 9 )}}$. In 2007, Lee et $\mathbf{a l}^{(\mathbf{1 )}}$ proved that $\alpha$-LA has a role to prevent lipid peroxidation and to support antioxidant system against oxidative damage in experimental model of arthritis. Moreover, $\alpha$-LA inhibited bone destruction in vivo and osteoclastogenesis in vitro

In the current study, daily administration of $\alpha$-LA daily from the beginning of CII injection for 42 days to rats of group III induced significant reduction of plasma level of LPO and $\mathrm{NO}$ as well as a significant increase in plasma level of SOD in rats of group III as compared with group II. These findings indicate that $\alpha$-LA could decrease lipid peroxidation and free radical formation and lead to a substantial recovery of one of the major antioxidant enzymes; SOD, thus limiting oxidative damage and decrease ROS formation, so, it could be considered as a protective agent against joint injury occurring in CIA. These results are in agreement with previous studies which recorded significant reduction of oxidative stress markers with marked increase in antioxidant levels in experimental model of arthritis after administration of $\alpha$-LA ${ }^{(48,60,61,62)}$.

Superoxide dismutase (SOD), which is a known antioxidant agent has been proved to have an antiinflammatory activity in several animal models of induced inflammation as in CIA rats. It was claimed that the SOD's antiinflammatory action is through prevention of formation of superoxide-dependent chemotactic activity $^{(63)}$. That action prevents the accumulation of inflammatory cells at the site of a potential lesion; thereby preventing all neutrophil-mediated cytotoxic events ${ }^{(64)}$. Various studies showed that $\alpha$-LA enhances SOD activity in rheumatoid arthritis models ${ }^{(64,65,66)}$. So, in the present study, increase level of SOD after administration of $\alpha$-LA could be one mechanism by which $\alpha$-LA exerts its activity in CIA rats.

Popa et al., $(2005)^{(67)}$ reviewed that rheumatoid arthritis (RA) is characterized by high concentrations of pro-inflammatory cytokines such as tumor necrosis factor a (TNF- $\alpha$ ), IL6, and interferon, especially in the synovial fluid but also in the 
circulation. The present study revealed an increase in serum level of TNF- $\alpha$ in CIA rats (group II). Additionally, the study revealed suppressing effect of lipoic acid on TNF- $\alpha$ in rats of group III. This was in accordance with the finding of Tastekin et al., (2007) ${ }^{(49)}$ who recorded increased serum level of TNF- $\alpha$ in CIA rats which revealed the key role of this pro-inflammatory cytokine in the pathogenesis of rheumatoid arthritis. Furthermore, they recorded significant decrease of TNF- $\alpha$ serum level with $\alpha$-LA treatment. Cytokines as TNF- $\alpha$ and IL-6 appear to be critically involved in the initiation and perpetuation of RA. These pro-inflammatory cytokines are considered to play a prominent role in RA pathogenesis by modulating cell migration, $\mathrm{T}$ and $\mathrm{B}$ cell activation, cartilage destruction, and synovial proliferation. Also, TNF$\alpha$ induced nuclear factor-kappaB (NF$\kappa \mathrm{B})$ activation which increase the severity of the inflammation in arthritis ${ }^{(68,69,70)}$.

Recent advances in arthritis treatment mainly focus on anti TNF- $\alpha$ agents $^{(71,72)}$. Regulation of cytokine levels in patients with RA may also be a novel approach to the treatment of these diseases ${ }^{(71)}$. In 2008, Aletaha et al., ${ }^{(72)}$ described the successful treatment of refractory RA by intravenous (IV) infusion of antibodies to TNF- $\alpha$, suggesting a key role for this cytokine in the pathogenesis of chronic arthritis. More recently in 2009, Yudoh et al., ${ }^{(30)}$ recorded that in the management of RA, anti-tumor necrosis factor (anti-TNF- $\alpha$ ) agents are becoming more widely available and offer the rapid onset of effective treatment. Several areas of investigation have indirectly implicated TNF- $\alpha$ as a contributor to cellular damage in CIA. High level of this cytokine can be interpreted as a progression of cartilage cell injury ${ }^{(73)}$.

In 2006, Kim et al., ${ }^{(74)}$ reported that both animal and human studies have strongly implicated TNF- $\alpha$ in the pathogenesis of RA. They demonstrated that $\alpha$-LA decreased the severity of inflammation and prevented joint destruction in collagen-induced arthritis mouse model via $\mathrm{NF}-\kappa \mathrm{B}$ down regulation. They suggested that amelioration of joint disease when treated with $\alpha$-LA was associated with reduction in oxidative stress, as well as inhibition of TNF- $\alpha$ induced NF- $\kappa B$ activation. From these findings, it could be exhibited that the possibility of a therapeutic effect of $\alpha$-LA in established RA by suppressing the release of this pro-inflammatory cytokine.

In 2009, Shay et al., ${ }^{(75)}$ reported that recent therapeutic strategies in RA aimed at mitigating oxidant production and oxidative damage. Reduction of severity of collageninduced arthritis in mice by $\alpha$-LA treatment is due to the reduction of inflammatory cytokines like TNF- $\alpha$, and partial inhibition of NF- $\kappa \mathrm{B}$ binding to DNA. Also, $\alpha$-LA inhibited osteoclast formation, suggesting that $\alpha$-LA may be useful in prevention of bone erosion and joint destruction in rheumatoid arthritis ${ }^{(76)}$.

The present study showed highly significant increase in inflammatory markers e.g., prostaglandin and $\mathrm{C}$ reactive protein $\left(\mathrm{PGE}_{2}\right.$ and $\left.\mathrm{CRP}\right) 6$ 
weeks after initial immunization with CII in rats of group II as compared with group I. Additionally, treatment of rats of group III with $\alpha$-LA showed significant reduction in inflammatory markers as compared with group II. These findings were in accordance with previous findings of other investigators $^{(\mathbf{2 3}, 37,49,77,78)}$. The antiinflammatory properties of $\alpha$-LA in humans have been investigated in a study carried by Sola et al., $(2005)^{(37)}$. It showed a significant decrease in serum TNF- $\alpha$, interleukin- 6 and other inflammatory markers following 4 weeks of supplementation with $\alpha$ LA (300 mg/day). Moreover, in 2007 , Smolen et al., ${ }^{(79)}$ reviewed that in rheumatoid arthritis there is a release of numerous pro-inflammatory mediators such as prostaglandins (PGs) and nitric oxide (NO).

\section{Conclusion:}

In conclusion, our study revealed that RA is a multifaceted disease for which additional treatments are still needed. The study showed that $\alpha$-LA has a role to prevent oxidative stress and to support antioxidant system against oxidative damage in this experimental arthritis model. Also, amelioration of joint damage in CIA rats by $\alpha$-LA was associated with inhibition of inflammatory process by lowering plasma level of TNF- $\alpha$, prostaglandin and C-reactive protein. These findings may encourage further exploration of the usefulness of lipoic acid in arthritis. Collectively, results of the present study indicate that $\alpha$-LA may be a new adjunctive therapy for rheumatoid arthritis as it has a potent antioxidant as well as antiinflammatory effects.

\section{Acknowledgment:}

I would like to express particular gratitude to Professor. Mahmoud Raaft Abd-El- Fadiel (Professor of Medical Physiology, Faculty of Medicine, Assuit University) for his helpful comments and critical reading of this manuscript.

\section{REFERENCES}

1. Lee EY, Lee CK, Lee KU. (2007): Alpha-lipoic acid suppresses the development of collagen-induced arthritis and protects against bone destruction in mice. Rheumatol Int 27:225233.

2. Bian L, Josefsson E, Bokarewa M, Tarkowski A and Magnusson M. (2009): Dichloroacetate alleviates development of collagen IIinduced arthritis in female DBA/1 mice. Arthritis Research \& Therapy, 11:R132.

3. Rice J, James M. Veal R. et al. (2008): Small Molecule Inhibitors of Hsp90 Potently Affect Inflammatory Disease Pathways and Exhibit Activity in Models of Rheumatoid Arthritis. ARTHRITIS \& RHEUMATISM 58: 12, 3765-3775.

4. Cush J, Pietschmann P, Oppenheimer-Marks N, Lipsky PE. (1992): The intrinsic migratory capacity of memory $\mathrm{T}$ cells contributes to their accumulation in rheumatoid synovium. Arthritis Rheum. 35:1434-1444.

5. Brennan FM and McInnes IB (2008): Evidence that cytokines 
play a role in rheumatoid arthritis. J Clin Invest, 118:3537-3545.

6. Segal B, Rhodus NL, Patel $\mathbf{K}$. (2008): Tumor necrosis factor (TNF) inhibitor therapy for rheumatoid arthritis. Oral Surg Oral Med Oral Pathol Oral Radiol Endod. 106:778-787.

7. Blanchard F, Duplomb L, Baud'huin M, Brounais B. (2009): The dual role of IL-6type cytokines on bone remodeling and bone tumors. Cytokine Growth Factor Rev, 20:19-28.

8. Haynes DR (2007): Inflammatory cells and bone loss in rheumatoid arthritis. Arthritis Res Ther. 9:104.

9. Okunishi K, Dohi M, Fujio K, Nakagome K, Tabata Y et al., (2007): Hepatocyte growth factor significantly suppresses collageninduced arthritis in mice. $J$ Immunol.179: 5504-5513.

10. Vlahopoulos S, Boldogh I, Casola A, Brasier AR. (1999): Nuclear factorkappaB- dependent induction of interleukin- 8 gene expression by tumor necrosis factor alpha: evidence for an antioxidant sensitive activating pathway distinct from nuclear translocation. Blood 94(6): 18781889.

11. Shi MM, Godleski JJ, Paulauskis JD. (1996): Regulation of macrophage inflammatory protein-1alpha mRNA by oxidative stress. $\mathrm{J}$ Biol Chem. 271(10):5878-5883.

12. Blake DR, Merry P, Unsworth J, Kidd BL et al., (1989): Hypoxic-reperfusion injury in the inflamed human joint. Lancet $\mathrm{i}: 289-293$.

13. Lunec J (1990): Free radicals: their involvement in disease processes. Ann Clin Biochem. 27:173-182.

14. Halliwell B, Gutteridge JM (1990): The antioxidants of human extracellular fluids. Arch Biochem Biophys. 280:1-8.

15. Gambhir JK, Lali P, Jain AK (1997): Correlation between blood antioxidant levels and lipid peroxidation in rheumatoid arthritis. Clin Biochem. 30:351355.

16. Babior B. (2000): Phagocytes and oxidative stress. Am J Med.109: 33-44.

17. Darlington $\mathbf{L}$ and Ramsey $\mathbf{N}$. (1993): Review of dietary therapy for rheumatoid arthritis. $\mathrm{Br} \mathrm{J}$ Rheumatol.32:507-14.

18. Susan M., Paul L, Betty P. (2005): Bcl-2 in endothelial cells is increased by vitamin $\mathrm{E}$ and $\alpha$ lipoic acid supplementation but not exercise training. J. Mol. Cell Cardiol., 38: 445-451.

19. Biewenga GP, Haenen GR, Bast A (1997): The pharmacology of the antioxidant lipoic acid. Gen Pharmac 29: 315-331.

20. Singh $U$ and Jialal I. (2008): Alpha-lipoic acid supplementation and diabetes. Nutr Rev. 66(11): 646-657.

21. Khanna $\mathbf{S}$ and Atalay $M$. (1999): a-lipoic acid supplementation: tissue glutathione homeostasis at rest and after exercise. J Appl Physiol 86: 1191-1196.

22. Packer L, Witt EH, Tritschler H (1995): Alpha-lipoic acid as a 
biological antioxidant. Free Radic Biol Med., 19: 227-250.

23. Smith A, Shenvi S, Widlansky M. (2004): Lipoic acid as a potential therapy for chronic diseases associated with oxidative stress. Curr Med Chem., 11:1135-1146.

24. Nandakumar K, Svensson $\mathbf{L}$, and Holmdahl R. (2003): Collagen type II-specific monoclonal antibody-induced arthritis in mice: description of the disease and the influence of age, sex, and genes. Am. J. Patho.l; 163:1827-1837.

25. Ferrandiz M, Maicas N, Garcia-Arnandis I and Terencio M. (2008): Treatment with a CO-releasing molecule (CORM-3) reduces joint inflammation and erosion in murine collagen-induced arthritis. Ann Rheum Dis., 67:1211-1217.

26. Terato K, Hashida R, Miyamoto $\mathrm{K}$, Morimoto $\mathrm{T}$ and Kata Y. (1982): Histological, immunological and biochemical studies on type II collagen arthritis in rats. Biomed Res; 3:495-523.

27. Thayer S. (1985): Serum lipid peroxides in rats treated chronically with adriamycin. Biochem. Pharmacol., 33 (14): 2259-2263.

28. Van Bezooijen L, Que I, Ederveen G, Klousterboer J and Lovik W. (1998): Plasma nitrate and nitrite level are regulated by ovarian steroids but do not correlate with trabecular bone mineral density in rats. $\mathrm{J}$. Endocrinology 159: 27-34.
29. Misra H. and Fridovich I. (1972): The role of superoxide anion in the auto-oxidation of epinephrine and a simple assay for superoxide dismutase. J. Biol. Chem., 215: 3170 - 3175.

30. Yudoh K, Karasawa R, Masuko K. (2009): Watersoluble fullerene (C60) inhibits the development of arthritis in the rat model of arthritis. International Journal of Nanomedicine 4: 217-225.

31. RINDFLEISCH A J and MULLER D. (2005): Diagnosis and Management of Rheumatoid Arthritis. American Family Physician 72; 61047.

32. Jones SA, Kennedy AJ, Roberts NA. (1982): Assessment of drugs for activity in established type II collagen arthritis. Agents Actions;12:650-6.

33. Muller-Ladner U. (1996): Molecular and cellular interactions in rheumatoid synovium. Curr Opin Rheumatol. , 8:210-20.

34. Ramprasath $\mathbf{V}$, Shanthi $P$ and Sachdanandam P. (2005): , Semecarpus anacardium Linn. nut milk extract, an indigenous drug preparation, modulates reactive oxygen/nitrogen species levels and antioxidative system in adjuvant arthritic rats, Mol Cell Biochem., 76: 97-104.

35. Jaswal S, Mehta H, Sood K and Kaur J. (2003): Antioxidant status in rheumatoid arthritis and role of antioxidant therapy, Clin Chim Acta 338: 123-129.

36. Gruzman A, Hidmi J, Katzhendler A. (2004): Synthesis and characterization of 
new and potent alpha-lipoic acid derivatives, Bioorg Med Chem 12 : 1183-1190.

37. Sola S, Mir M, Cheema F, and Parthasarathy T. (2005): lipoic acid improve endothelial function and reduce markers of inflammation in the metabolic syndrome: results of the Irbesartan and Lipoic Acid in Endothelial Dysfunction (ISLAND) study, Circulation 111: 343-348.

38. Sundaram K and Panneerselvam S. (2006): Oxidative stress and DNA single strand breaks in skeletal muscle of aged rats: role of carnitine and lipoic acid, Biogerontology 7 (2): 111-118.

39. Park H, Lee H, Son D. (2004): Inhibition of Inflammation Mediator Generation by Suppression of NF-_B Through Interaction With the p50 Subunit. ARTHRITIS \& RHEUMATISM , 50:11, 3504-3515.

40. Kuwamoto M, Okano T, Fukata $S$ and Hiroshi $H$. (2007): Effects of sciatic neurectomy on arthritis and bone loss in rats with collagen-induced arthritis. Yonago Acta medica 50:57-63.

41. Martín A, Castillero E, Granado $M$, and LópezCalderón A. (2008): Adipose tissue loss in adjuvant arthritis is associated with a decrease in lipogenesis, but not with an increase in lipolysis. Journal of Endocrinology 197, 111-119.

42. Granado M, Martín A, Priego T, López-Calderón A \& Villanúa A. ( 2006): TNF blockade did not prevent the increase of muscular MuRF-1 and MAFbx in arthritic rats. Journal of Endocrinology 191: 319-326.

43. Simons $\mathbf{J}$, van den Pangaart $\mathbf{P}$, van Roomen C, Aerts J \& Boon L (2005): Cytokine-mediated modulation of leptin and adiponectin secretion during in vitro adipogenesis: evidence that tumor necrosis factor-alpha and interleukin-1beta-treated human preadipocytes are potent leptin producers. Cytokine 32: 94-103.

44. Lacasa D, Taleb S, Keophiphath M, Miranville A \& Clement K. (2007): Macrophage-secreted factors impair human adipogenesis: involvement of proinflammatory state in preadipocytes. Endocrinology 148: 868-877.

45. Mulherin D, Thurnam D, Situnayake D. (1996): Glutathione reductase activity, riboflavin status and disease activity in rheumatoid arthritis. Ann Rheum Dis., 55:837-41.

46. Sklodoswka M, Gromadzinska J, Biernacka M. (1996): Vitamin $\mathrm{E}$, thiobarbituric acid reactive substance concentrations and superoxide dismutase activity in the blood of children with juvenile rheumatoid arthritis. Clin Exp Rheumatol., 14:433-9.

47. Hitchon $\mathbf{C}$ and El-Gabalawy $\mathbf{H}$. (2004): Oxidation in rheumatoid arthritis, Arthritis Res Ther 6 (6): 265-278.

48. Matyska-Piekarska E, Luszczewski A, Lacki $A$ and Waver A. (2006): The role of oxidative stress in the etiopathogenesis of rheumatoid 
arthritis, Postepy Hig Med Dosw 60: 617-623.

49. Tastekin N, Usta U, Dokmeci D, Aydogdu N. (2007): Protective effects of 1-carnitine and alphalipoic acid in rats with adjuvant arthritis. Pharmacol Res., 5: 303310.

50. Halliwell B and Hoult. (1998): Blake, Oxidants, inflammation, and anti-inflammatory drugs, FASEB $J_{2}$. 2867-2873.

51. Key L, Wolf C, Gundberg M, Ries L. (1994): Superoxide and bone resorption. Bone 15:431-6.

52. Tiku M, Shah $\mathbf{R}$ and Allison G. (2000): Evidence linking chondrocyte lipid peroxidation to cartilage matrix protein degradation: possible role in cartilage aging and the pathogenesis of osteoarthritis. J Biol Chem. ;275:20069-76.

53. Tawara T, Shingu M, Nobunaga M, Naono T. (1991): Effects of recombinant human IL1 on production of prostaglandin E2, leukotriene B4, NAG, and superoxide by human synovial cells and chondrocytes. Inflammation 15:145-57.

54. Monboisse J, Gardes-Albert M and Randoux A. (1988): Collagen degradation by superoxide anion in pulse and radiolysis. Biochim Biophys Acta.;965:29-35.

55. Moreno J and Pryor W. (1992): Inactivation of 1-proteinase inhibitor by peroxynitrite. Chem Res Toxicol ;5:425-31.

56. Campo G, Avenoso A, Campo $\mathrm{S}$ et al.,. (2003): Efficacy of treatment with glycosaminoglycans experimental collagen-induced arthritis in rats. Arthritis Res Ther. 5:122-131.

57. Gambhir J, Lali P, Jain A. (1997): Correlation between blood antioxidant 58 levels and lipid peroxidation in rheumatoid arthritis. Clin Biochem 30:351355.

58. Cuzzocrea S, Mazzon E, Di Paola R, et al., (2005): Effects of Combination M40403 and Dexamethasone Therapy on Joint Disease in a Rat Model of Collagen-Induced Arthritis. ARTHRITIS \& RHEUMATISM 52 (6): 1929-1940.

59. Arivazhagan, P. and Panneerselvam C. (2002): Effect of DL- $\alpha$ - lipoic acid on neural antioxidants in aged rats. Pharm. Res., 42: 219-222.

60. Hagen T, Liu J, Lykkesfeldt J, Wehr C. (2002): Feeding acetylL-carnitine and lipoic acid to old rats significantly improves metabolic function while decreasing oxidative stress. Proc Natl Acad Sci USA 19;99(4):1870-5.

61. Olsen $\mathbf{N}$ and Stein C. (2004): New drugs for rheumatoid arthritis. N Engl J Med; 350:2167-79.

62. O'Dell JR. (2004): Therapeutic strategies for rheumatoid arthritis. N Engl J Med; 350:2591-602.

63. Petrone W, English D, Wong K and McCord J. (1980): Free radicals and inflammation: superoxide-dependent activation of a neutrophil chemotactic factor in plasma, Proc Natl Acad Sci USA 77: 1159-1163. 
64. Sundaram K and

Panneerselvam S. (2006):

Oxidative stress and DNA single strand breaks in skeletal muscle of aged rats: role of carnitine and lipoic acid, Biogerontology 7: 111-118.

65. Sumathi R, Jayanthi S, Kalpanadevi $\quad \mathrm{V}$ and Varalakshmi P. (1993): Effect of dl-alpha-lipoic acid on tissue lipid peroxidation and antioxidant systems in normal and glycollate treated rats, Pharmacol Res 27 (4): 309-318.

66. Sahin M, Sağdiç G, Elmas O and Aslan $M$ et al., (2006): Effect of chronic restraint stress and alpha-lipoic acid on lipid peroxidation and antioxidant enzyme activities in rat peripheral organs, Pharmacol Res 54 (3): 247-252.

67. Popa C, Netea M, Radstake T. (2005): Markers of inflammation are negatively correlated with serum leptin in rheumatoid arthritis. Ann Rheum Dis ;64:1195-1198.

68. Firestein GS, Alvaro-Gracia J, Maki R. (1990): Quantitative analysis of-69- ytokine gene expression in rheumatoid arthritis. J Immunol ;145:1037.

69. Connell L, McInnes IB. (2006): New cytokine targets in inflammatory rheumatic diseases. Best Pract Res Clin Rheumatol. 20(5):865-878.

70. Dixon W, Symmons D, Lunt $M$ et al, (2007): Serious infection following anti-tumor necrosis factor alpha therapy in patients with rheumatoid arthritis.
Arthritis Rheum. 56; (9): 28962904.

71. Wolfe $F$ and Michaud $K$. (2007): Biologic treatment of rheumatoid arthritis and the risk of malignancy: analyses from a large US observational study. Arthritis Rheum. 56(9):28862895.

72. Aletaha D, Strand V, Smolen J. (2008): Treatment-related improvement in physical function varies with duration of rheumatoid arthritis: a pooled analysis of clinical trial results. Ann Rheum Dis. 67(2):238-243.

73. Feldmann M, Brennan F, Foxwell B, Maini R. (2001): The role of TNF-alpha and IL-1 in rheumatoid arthritis. Curr Dir Autoimmun, 3:188-199.

74. Kim HJ, Chang EJ, Kim HM. (2006): Antioxidant alpha-lipoic acid inhibits osteoclast differentiation by reducing nuclear factor-kappaB DNA binding and prevents in vivo bone resorption induced by receptor activator of nuclear factorkappaB ligand and tumor necrosis factor-alpha. Free Radic Biol Med.;40(9):1483-1493.

75. Shay K, Smith E and Petersen K. (2009): Alpha-lipoic acid as a dietary supplement: Molecular mechanisms and therapeutic potential. Biochmica et Biophysica Acta 1790: 1149-60.

76. Bai XC, Lu D, Liu AL. (2005): Reactive oxygen species stimulates receptor ctivator of NF-kappaB ligand expression in osteoblast. $J$ Biol Chem.;280(17):17497-17506. 
77. Bast A and Haenen GR. (2003): Lipoic acid: a multifunctional antioxidant. Biofactors ;17:207213.

78. Zhang $\mathbf{W}$, Wei $\mathbf{H}$, Hagen $\mathbf{T}$ and Frei B. (2007): Alpha-lipoic acid attenuates LPS-induced inflammatory responses by activating the phosphoinositide 3kinase/Akt signaling pathway, Proc. Natl. Acad. Sci. USA 104: 4077-4082.

79. Smolen J, Aletaha D, Koeller M. (2007): New therapies for treatment of rheumatoid arthritis. Lancet;370: 1861-74.

\section{تأثيرات حض ألفا ليبويك المضادة للاككسة والالتهاب على التهاب المفاصل الروماتويدي المستحدث بالكولاجين الثاني في الفئران}

$$
\text { قسم الفسبولوجيا الطبية، كلبة الطب القبن-جامعة أسبوط }
$$

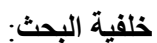

التهاب المفاصل الروماتويدي هو التهاب مزمن متز ايد بالمفاصل غير محدد السبب، يتميز هذا المرض التهن بالتهاب

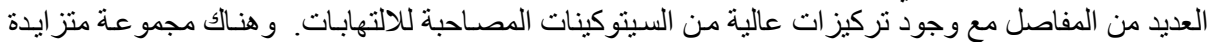

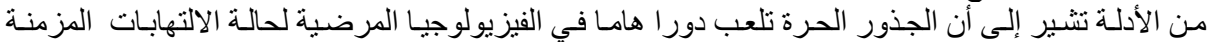

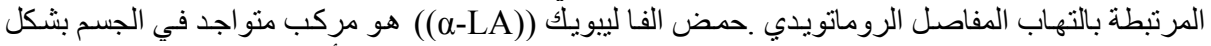

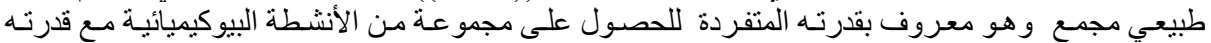
البيولوجية قوية المفعول كمضاد للأكسدة. أيضا ، له دور في تغيير مسالك الإشار ات المختلفة الخاصة بالالتهاب التهاب. الهُف من البحث:

الغرض من هذه الدر اسـة تقييم فعالية حمض الفـا ليبويك (

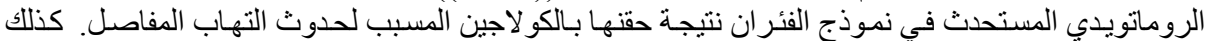

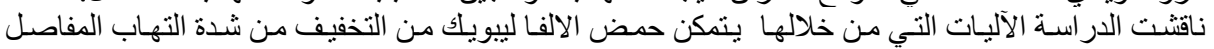
الروماتويدي.

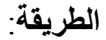

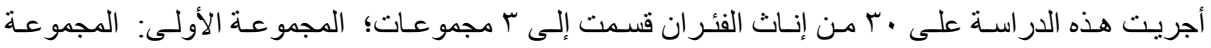

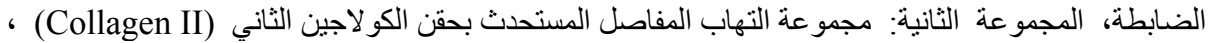

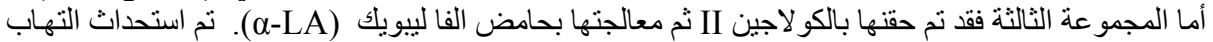

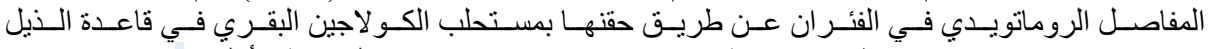

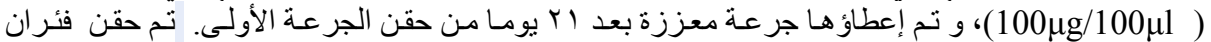

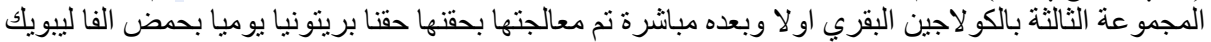
(Q-LA)

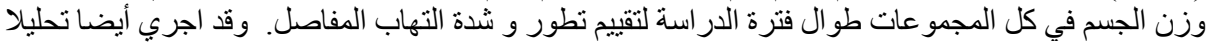

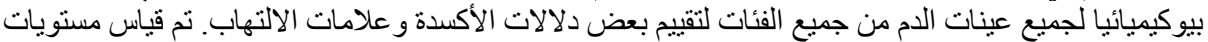

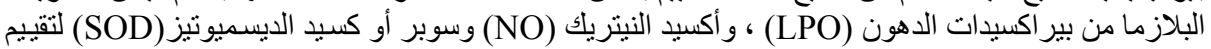

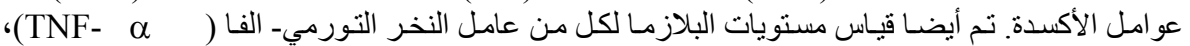

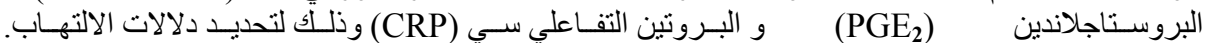
النتائج:

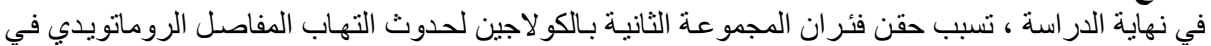
جميع مظاهره لكل فئر ان هذه المجمو عة مع انخفاض تدريجي في وزن الجسم استمر حتى نهايـة التجربـة .أدى التى 


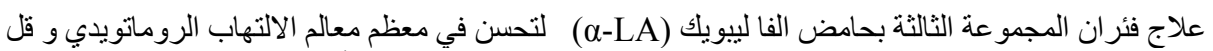

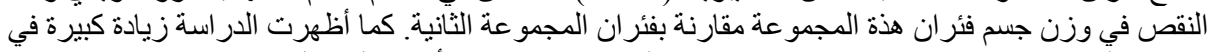

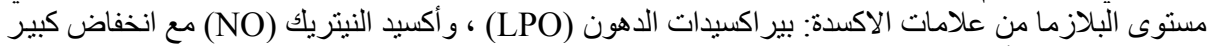

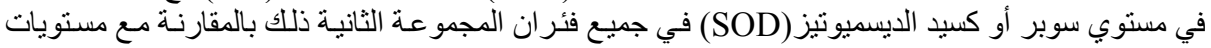

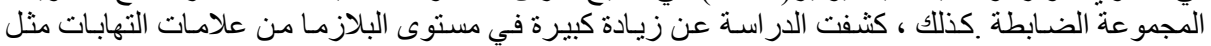

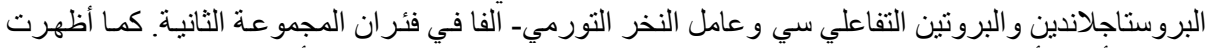

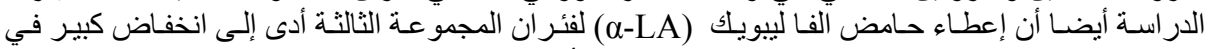

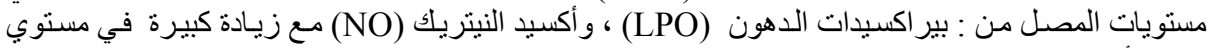

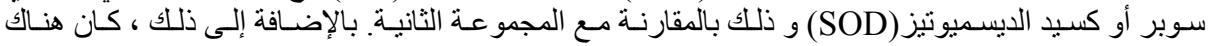

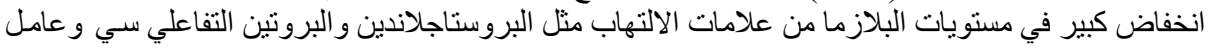

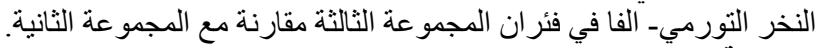

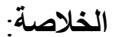

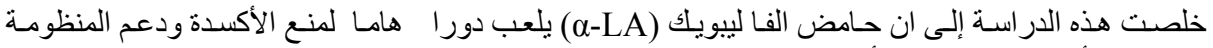

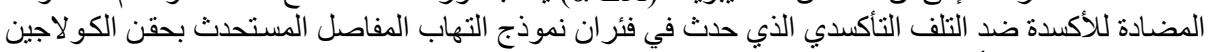

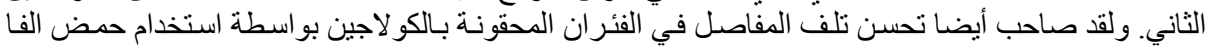

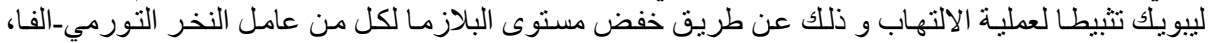

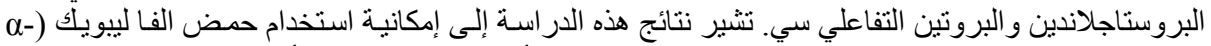

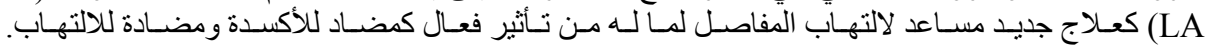

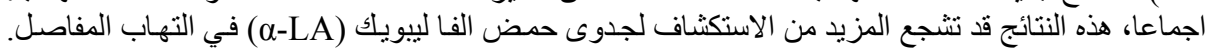

